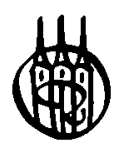





\section{Grundgebiete der Elektrotechnik 1}

Gleichstromnetze, Operationsverstärkerschaltungen, elektrische und magnetische Felder

von

Prof. Dr.-Ing. Horst Clausert,

TU Darmstadt

Prof. Dr.-Ing. Gunther Wiesemann,

FH Braunschweig/Wolfenbüttel

9. Auflage

Mit 264 Bildern und 5 Tabellen 
Bibliografische Information Der Deutschen Bibliothek

Die Deutsche Bibliothek verzeichnet diese Publikation in der Deutschen Nationalbibliografie; detaillierte bibliografische Daten sind im Internet über $<$ http://dnb.ddb.de $>$ abrufbar.

(C) 2005 Oldenbourg Wissenschaftsverlag GmbH

Rosenheimer Straße 145, D-81671 München

Telefon: (089) 45051-0

www.oldenbourg-verlag.de

Das Werk einschließlich aller Abbildungen ist urheberrechtlich geschützt. Jede Verwertung außerhalb der Grenzen des Urheberrechtsgesetzes ist ohne Zustimmung des Verlages unzulässig und strafbar. Das gilt insbesondere für Vervielfältigungen, Übersetzungen, Mikroverfilmungen und die Einspeicherung und Bearbeitung in elektronischen Systemen.

Lektorat: Kathrin Mönch

Herstellung: Rainer Hartl

Umschlagkonzeption: Kraxenberger Kommunikationshaus, München

Gedruckt auf säure- und chlorfreiem Papier

Druck: R. Oldenbourg Graphische Betriebe Druckerei GmbH

ISBN 3-486-27575-5 